\title{
Determinants of Entertainment and Apparel Expenditures in an American Household
}

\author{
Belinda Luna-Pulido ${ }^{1}$, Kruti Lehenbauer ${ }^{2}$ \\ ${ }^{I}$ DBA Student, University of the Incarnate Word, San Antonio, U.S.A., bcastrej@student.uiwtx.edu \\ ${ }^{2}$ Associate Professor, University of the IncarnateWord, San Antonio, U.S.A.Lehenbau@uiwtx.edu
}

\begin{abstract}
Distinct characteristics of households play an important role in the decisions made regarding expenditures. This study identifies what specific characteristics of households drive the decisions to make specific purchases such as entertainment and apparel using the Consumer Expenditure Survey Data from the Bureau of Labor Statistics (BLS, 2018) for the years 2016-17. First, we follow the log-lin regression model methodology to identify if there are clear disparities in purchasing decisions based upon the gender of the head of household $(\mathrm{HH})$ and then present sub-models to identify the determinants of expenditures on apparel and entertainment for a household based upon characteristics such as income of the household, age of the head of the household, family size, number of children below age five in the household, number of earners in the household, education of the head of the household, and race and ethnicity of the head of the household as our primary independent variables. Primary model results show that there are clear differences in the determinants of total expenditures based on the sex of the head of the household. Our sub-models show that male-headed households spend more on entertainment, whereas female-headed households spend more on apparel than their counterparts.
\end{abstract}

KEYWORDS: Consumer behavior, household purchases, BLS DataSet, STATA 15, Regression Analysis, Log-Lin Regression

\section{Introduction}

There is a variety of identifiable factors from consumer feedback based on past purchasers that contribute to future sales within new and existing consumers of a certain product. Producers and suppliers aim to understand consumer behaviors and characteristics to deliver products that are relevant and meet customer expectations when making purchasing decisions. Past research on consumer buying behaviors, shows that consumer feedback through word-of-mouth (WOM) or through electronic-wordof-mouth (EWOM) is a strong driving factor in consumer purchases (Balter \& Butman, 2005). Moreover, the fundamental characteristics of a household such as total income, number of members in the family, area of residence, and the sex of the decision maker in the household do matter for the decisions that the household makes in terms of its expenditures. The purpose of this study is to show which factors impact the consumption of entertainment and apparel products in a household.

Even though we begin with a short literature review of the qualitative nature of EWOM and WOM and how they impact consumer decision-making regarding purchasing products online or in stores, it is important to note that our dataset does not contain this information and therefore we have not been able to include it in our models or results. Given that existing research has shown that positive and negative reviews impact sales (Hu, Liu, \& Zhang 2008), we find it crucial to include it in the literature analysis on this subject. Thereafter, we create a general model of consumer behavior based on individual characteristics and demographics and include the entertainment and apparel expenditures of a household as separate factors from all other expenditures with a view to identifying what household characteristics contribute toward these purchases. The primary hypothesis for this paper is to identify whether factors such as consumer household/personal income, monthly household expenditures of the consumer, and other exogenous demographic and socio-economic factors impact purchasing decisions regarding consumption of specific products within households.

\section{Literature Review}

Surveys shows that reviews from other consumers are one of the top influences on whether new and potential consumers buy a product. Products with more positive or favorable reviews were found to 
have a higher sales-rate than other products based on the surveys conducted by Fagerstrom, Ghinea \& Sydnes (2015). Yelp and TripAdvisor are two key websites and applications where customers seek and share reviews of products and services available in local areas (Wright 2015). Third party reviews such as those that are available for automobile sales on Kelly Blue Book and Edmunds websites demonstrate that consumers who visit and are active on these review sites provide information about various automobiles and thereby influence sales by word of mouth (WOM) method (Bahety 2016).

Keller \& Fay (2012) conducted interviews on a weekly, monthly, and annual basis for about 36,000 participants between the ages of 13 and 69 in the United States to gather information on how word-of-mouth (WOM) and Electronic word-of- mouth (EWOM) could potentially influence the digital marketplace. The results determined that $90 \%$ of WOM conversations took place offline, while $8 \%$ were online, or EWOM. Out of the EWOM, about $32 \%$ related to entertainment brands, TV shows, and movies as compared to only $9 \%$ in the WOM settings (Keller \& Fay 2012). Thus, entertainment expenditures are heavily influenced by the reviews of the product/service that are obtained through WOM or EWOM.

$\mathrm{Hu}$, Liu \& Zhang (2008) found that if there are more reviews about a product, consumers tend to be more trusting of the product (or merchant) and are likely to believe that product has a better value. Consumers have been found to make decisions based on e-commerce websites by reviewing variables such as price, quality, ordering, delivering, and evaluation of the product (Shih, 2010). Consumers depended upon their perceptions of the delivery costs, risk factors, and enjoyment factors when making their decisions regarding shopping for products or services (Yousaf, Altaf, Sarwar, \& Shah 2012).

Other factors such as demographic and socio-economic background of consumers affects their spending decisions. Education has been found to be an important determinant of satisfaction attained by customers who make purchases. The data from Flexible Consumer Behavior Survey (FCBS) shows that households with higher education and income had higher expenditures on food, whether eaten out-of-home or purchased for home consumption (Tang, et al. 2016). Research conducted over household expenditures in the Neilson Homescan panel showed that if there the head of the household is a female, then higher levels of education of the head of the household result in a lower consumption of beef, fats and oils and increased consumption of fish and seafood, fresh fruits, and fresh vegetables (Zhen, Taylor, Muth, \& Leibtag 2009). More educated consumers are likely to seek more information and rely less on advertisements when they need specific information regarding products (Harris \& Shiptsova 2007). Thus, the levels of education of the primary decision-makers in a household do impact the purchasing decisions of a household.

Charron-Chénier \& Mueller (2018) demonstrates that acquiring essential goods and services places different levels of financial burden to different families. The study reviewed AfricanAmerican and white families and determined that racial disparities are seen in terms of insurance coverage because black households had more private insurance resulting in poorer coverage at higher costs (Charron-Chenier \& Mueller 2018). Data obtained from the 1984 Consumer Expenditure Interview survey show that as household income changes, redistributions of expenditures occur and that younger consumers tend to focus on products that are inexpensive and more durable as compared to older consumers who are less price-sensitive to products. Older consumers also focus more on household expenditures to pay for needed medical supplies and services (Sawtelle 1993). The number of members in a household, the head of the household, single or marital status of the head of the household, employment status of members in the household, and number of young children impact the budget share on specific expenditures within a household (Kalwij \& Salverda 2007).

It is interesting to see how the gender of the head of the household impacts the expenditures and consumption patterns of a given household. As compared to male-headed households, femaleheaded households consume most of their income by spending on education and food with lower expenditures on durable goods, consumer goods, housing, and other items (Fatima \& Ahmad 2013). This relationship between gender and household expenditures patterns in households was also 
confirmed in Ghana using data form the Living Standard Survey round four (GLSS 4) 1998-99 by Guzman, Morrison, and Sjoblom (2008).

Socio-demographic characteristics such as age sex, family income, and family size also contribute to the expenditures on leisure or entertainment activities (Scheerder, Vos, \& Taks, 2011). Finding niche markets for apparel would be beneficial to a producer or supplier because the age and characteristics of the potential consumer plays a significant role in determining how much a consumer is willing and able to pay for clothing and related products (Bahng, Y., \& Kincade, D. 2013). Purchase decisions are made based on garment prices, age of consumer, employment status of decision-maker, gender, region of residence, and the presence of children in the family (Fadiga, Misra, \& Ramirez 2005).

Thus, we find that consumers make purchases based on their own demographic characteristics and reviews from other consumers. There is a large target market for apparel and entertainment expenditures, which are both highly price-elastic within households. Businesses can benefit from understanding the importance of the characteristics of their target consumers and recognizing the influence of consumer reviews on potential consumers. This type of care while making marketing or promotional decisions can help increase the revenues for businesses in the apparel and entertainment industries.

\section{Methodology and Data}

As seen from the literature review section, characteristics such as income, race, age, and gender impact purchasing decisions of consumers. We use the data obtained for the years 2016-2017 from the Consumer Expenditure Surveys collected by the Bureau of Labor Statistics (BLS) for estimating our models. This dataset contains detailed information regarding expenditures, income, and demographic characteristics of households and consumers in the United States (BLS, 2018). An Ordinary Leastsquares Regression (OLS) general model will be used to conduct analysis of the data to determine how demographic characteristics of consumers impact their total household expenditures, and thereby their choices. The examination of household expenditures and consumer demographics will provide insight regarding the driving factors of sales of consumer goods in general, before we shift our focus to the specific characteristics that determine the apparel and entertainment expenditures of a household. Table 1 shows the key descriptive statistics for this dataset that covers a total of 5 quarters.

Since our focus is to identify what drives the expenditures among consumers in the United States, our primary dependent variable is totexp or the calculated total expenditure for each consumer unit (family). Out of the $60,000+$ observations, only about 31,469 observations did not have missing data. Moreover, even within this data, there were some obvious errors such as values of zero assigned to total household expenditures. We were able to eliminate the missing and erroneous observations by considering the natural log of the totexp variable, which resulted in a total of 20,964 observations that were usable. Similar exercises on the entertainment expenditure and apparel expenditure produced only 2327 and 11,559 valid observations.

The independent variables can be split into two main categories: household income variables and household characteristics. Upon taking a natural log of the totinc variable, we were left with about 28,817 observations with valid data on income. Some of the key observations from the data, as seen in Table 1, are that about $47 \%$ of the households have males as the head of the household, and $51 \%$ of the households have heads of households that are married. Moreover, if we go by the race and ethnicity of the head of the household, $69 \%$ of the households are non-Hispanic white, $11 \%$ are non-Hispanic black, and $13 \%$ are Hispanic. The average family size is about 2.44 members with a standard deviation of 1.47 demonstrating that about $67 \%$ of the households have between 1 and 4 members in the sample. $89 \%$ of the households live inside a MSA and the average number of cars owned per household is 0.85 with a standard deviation of 0.85 , demonstrating that a majority of households have between 0 and 2 automobiles. $24 \%$ of the households have members older than 64 living with them whereas $31 \%$ of the households have children under the age of 5 .

General Regression MODEL 1: This base model is based on the Fatima \& Ahmed (2013) estimates where the dependent variable is totexp and the independent variables are Age, FamSize, 
Propchild5, Propmem65, NumEarner, totinc, and roomsq, separately estimated for Male-headed and Female-headed households.

Table 1. Descriptive statistics for Dependent and Independent Variables

\begin{tabular}{|c|c|c|c|c|c|c|}
\hline Variable & Description & $\mathbf{N}$ & Mean & SD & Min & Max \\
\hline \multicolumn{7}{|c|}{ Dependent Variables } \\
\hline \multicolumn{7}{|l|}{ Expenditures } \\
\hline totexp & Total calculated other expenditures & 31649 & 33,315 & 42,611 & 0 & 899,000 \\
\hline Intotexp & Natural log of total expenditures & 20964 & 10.55 & 0.76 & 3.47 & 13.71 \\
\hline entertainexp & Entertainment expenditures & 31649 & 148 & 3,657 & 0 & 367,000 \\
\hline Inentexp & Natural log of entertainment expenditures & 2327 & 6.04 & 1.51 & 0.98 & 12.81 \\
\hline apparexp & Total annual apparel and service expenses & 31649 & 296 & 1,303 & 0 & 168,000 \\
\hline Inappexp & Natural log of apparel and service expenses & 11559 & 4.52 & 1.31 & -1.1 & 10.65 \\
\hline \multicolumn{7}{|c|}{ Independent Variables } \\
\hline \multicolumn{7}{|c|}{ Household Income } \\
\hline totinc & Total calculated income for Household & 31649 & 63,087 & 83,438 & 0 & $2,020,000$ \\
\hline Intotinc & Natural log of Total Income & 28817 & 10.56 & 1.27 & 0 & 14.52 \\
\hline \multicolumn{7}{|c|}{ Household Characteristics } \\
\hline sex & $=1$ if $\mathrm{HH}$ is male, 0 otherwise & 31649 & 0.47 & 0.5 & 0 & 1 \\
\hline age & age of reference person & 31649 & 51.71 & 17.49 & 16 & 87 \\
\hline white & $=1$ if non-Hispanic white, 0 otherwise & 31649 & 0.69 & 0.46 & 0 & 1 \\
\hline black & $=1$ if non-Hispanic black, 0 otherwise & 31649 & 0.11 & 0.31 & 0 & 1 \\
\hline Hispanic & $=1$ if Hispanic Origin, $\mathrm{O}$ otherwise & 31649 & 0.13 & 0.34 & 0 & 1 \\
\hline otherrace & $=1$ if non-Hispanic other race, 0 otherwise & 31649 & 0.07 & 0.25 & 0 & 1 \\
\hline education & Education of Reference person & 31649 & 4.41 & 1.68 & 0 & 7 \\
\hline married & $1=$ ref person is married, 0 otherwise & 31649 & 0.51 & 0.5 & 0 & 1 \\
\hline FamSize & total members in household & 31649 & 2.44 & 1.47 & 1 & 15 \\
\hline numchild & No. of children younger than 17 in family & 31649 & 0.5 & 0.97 & 0 & 10 \\
\hline propchild5 & proportion of children $<5$ & 31649 & 0.31 & 0.53 & 0 & 4 \\
\hline propmem65 & proprotion of members $>64$ & 31649 & 0.24 & 0.4 & 0 & 1 \\
\hline NumEarner & number of CU members earning income & 31649 & 1.26 & 0.97 & 0 & 10 \\
\hline roomsq & number of rooms in CU living quarters & 31338 & 5.85 & 2.24 & 1 & 69 \\
\hline smsastat & $=1$ if reside inside MSA, 0 otherwise & 31649 & 0.89 & 0.31 & 0 & 1 \\
\hline NumAuto & total number of owned cars & 31649 & 0.8 & 0.85 & 0 & 11 \\
\hline
\end{tabular}

Source: Consumer Expenditure Surveys 2016-2017 (BLS, 2018)

Keeping in line with how literature generally accounts for the non-linear aspects of expenditure and income, we create a slightly different model by using natural log values of expenditures and income. We also expand this model by adding other exogenous variables to test for other factors that could impact expenditures within a household. Thus, the expanded models with dependent variable lntotexp are as given below. It is important to note here that since these are Log-Lin Models, the interpretations of the slopes obtained have to be done with more care.

Log-Lin General Model, MODEL 2: This model is similar to Model 1 but with lntotexp being the dependent variable and the independent variables being Age, FamSize, PropChild5, Propmem65, NumEarner, Intotinc, roomsq, smsastat, education, white, black, Hispanic, NumAuto, and married. The focus of this paper is to show what factors play a role in the decisions to spend money on entertainment and apparel in households. To that end, we include the expenditures made on entertainment and apparel as independent variables in the Log-Lin General Model to find if they impact the total expenditures of a household significantly or not.

General Model with Entertainment and Apparel expenditures included, MODEL 3: This model is an expansion of Model 2 with lnentexp and lnappexp being additional independent variables included. To identify the factors that impact the expenditures on entertainment and apparel in a household, we will run two additional models with the dependent variables identified as the lnentexp and lnappexp, including the total expenditure of the household as an independent 
variable. We start by estimating the model by including the sex of the head of the household as an independent variable, and later split each Model into parts (a) and (b) by Female and Male head of household.

Log-lin Models with Entertainment/Apparel as dependent variables, MODELS 4 and 5: These models have lnentexp and lnappexp as dependent variables respectively. The independent variables included in this model are Age, FamSize, PropChild5, Propmem65, NumEarner, Intotinc, roomsq, smsastat, education, white, black, Hispanic, NumAuto, married, and sex. We estimate these models by head of household separately as well, by removing the sex variable.

\section{Results}

Before we discuss the results of the models that we estimated using STATA 15.0, it would be interesting to study the fundamental differences between male-headed and female-headed households in terms of their total income levels and total expenditure levels, with special focus on entertainment and apparel expenditures. It is important to note that we have assigned male-headed and female-headed households based upon the reference person who responded to the survey. We are making a big assumption, therefore, that these individuals are indeed the respective head of the households. So, we must be careful while interpreting these data. However, if we function under the assumption that if the reference person is indeed the one who is proactively responding to the survey, they might very well be the individual in the household who makes key expenditure-related decisions.

Table 2 indicates that the mean income for male-headed households is about $\$ 14,000$ more than that for female-headed households. The mean expenditures are also higher in male-headed households, but only marginally, by about $\$ 2,000$ per year. The variance suggests that there is more fluctuation in income and expenditures in male-headed households as compared to female-headed households. About $47 \%$ of the households in our dataset are headed by males with females heading the remaining 53\% of the households. Moreover, the entertainment and apparel expenditures are drastically different between the two types of households. Male-headed households have lower average expenditures on entertainment as compared to female-headed households, but the standard deviations show that the fluctuations are higher in male-headed households for entertainment expenditures than their counterparts. On the other hand, when considering apparel related expenditures, male-headed households have lower mean expenditures and a lower standard deviation showing that female-headed households spend more on apparel as compared to their counterparts.

Now, let us consider the results from our base and modified models, namely Models 1, 2, and 3 that use totexp as the dependent variable to understand the differences in the characteristics of household expenditure and consumption among male and female-headed households.

Model 1 Results: With an intercept of $\$ 2,870.62$ and $\$ 1,255.10$ for male versus femaleheaded households in Model 1 results, there is a marked, albeit statistically insignificant, difference between the base level spending between the two types of households, if all the other variables had a value of 0 . Each additional year of age of the head of the household increases the expenditures by $\$ 83$ in male-headed and $\$ 87$ in female-headed households. Each additional member in the family increases the expenditures by about $\$ 1526$ for male-headed and $\$ 949$ for female-headed households. The curious outcome is the impact of an increase in the number of children below the age of five in each type of household. Male-headed households show a decline in total expenditures while female-headed households show an increase in the total expenditures. Since these values are not statistically significant in Model 1 , we cannot say with any certainty if this is indeed the case. Additional earners in the family unit increases expenditures by about $\$ 1269$ for male-headed households, and a whopping \$2630 (more than double) for female-headed households. For each added dollar of income, the household expenditure increases by 12 cents for male-headed households versus 14 cents for their counterparts. Each additional room in the residence increases the total annual expenditure by $\$ 2,352$ for male-headed and $\$ 2,196$ for female-headed households, 
indicating that there is no significant difference in the impact of number of rooms between the two types of households.

Table 2. Total Income and Total Expenditure Summaries by Sex of Head of Household

\begin{tabular}{|c|cccc|c|}
\hline & $\begin{array}{c}\text { Mean } \\
\text { Income }\end{array}$ & $\begin{array}{c}\text { Mean } \\
\text { Expenditures } \\
\text { (Std. Dev.) }\end{array}$ & $\begin{array}{c}\text { Mean Entertain } \\
\text { Expenses } \\
\text { (Std. Dev.) }\end{array}$ & $\begin{array}{c}\text { Mean Apparel } \\
\text { Expenses } \\
\text { (Std. Dev.) }\end{array}$ & $\begin{array}{c}\text { Frequency } \\
\text { Percentage }\end{array}$ \\
\hline Female & $56,483.26$ & $32,456.92$ & 122.49645 & 314.76283 & 16,708 \\
& $(76,390)$ & $(41,090)$ & $(2,403)$ & $(1,587)$ & $\mathbf{5 2 . 7 9 \%}$ \\
Male & $70,471.28$ & $34,275.34$ & 175.84133 & 275.47884 & 14,941 \\
& $(90,105)$ & $(44,232)$ & $(4,676)$ & $(882)$ & $\mathbf{4 7 . 2 1 \%}$ \\
\hline Total & $63,086.79$ & $33,315.37$ & 147.67974 & 296.21747 & 31,649 \\
& $(83,438)$ & $(42,611)$ & $(3,657)$ & $(1,303)$ & $\mathbf{1 0 0 . 0 0 \%}$ \\
\hline
\end{tabular}

Source: Consumer Expenditure Surveys 2016-2017 (BLS, 2018)

Model 2 Results: For Model 2, we have used the Log-Lin Model and expanded the number of independent variables included in the base model, to capture some of the observations from the literature. We have also considered the natural log of the total income instead of the totinc variable, which accounts for a partial log-log model. Thus, we must be cautious while interpreting the results from the regression analysis. The intercept does not reflect a significant difference between male and female-headed households. Each added year of age of head of household increases total expenditures by $0.2 \%$ in male-headed and $0.3 \%$ in female-headed households. If family size increases by 1 member, the expenditures for both types of households increase by a comparable $4.4 \%$. Here, the most interesting result lies in the impact of an additional child below the age of five. In male headed households, the impact is not significant but in female-headed households, the total expenditures increase by about 3.6\% per year! All other variables except the race and ethnicity variables behave similarly for both types of households. Race and ethnicity variables are compared to the omitted category of otherraces, which includes Asian, Pacific-Islanders, mixed-race, and unknown. Non-Hispanic white, non-Hispanic black, and Hispanic are all mutually exclusive categories. Results of Model 2 show that white male-headed households spend equivalently to male-headed households of otherraces (coefficient is not statistically significant) but black maleheaded households spend about $12 \%$ less and Hispanic male-headed households spend about $6.7 \%$ less than the otherrace male-headed households. On the female-headed households front, all three, namely white, black, and Hispanic female-headed households spend $6.6 \%, 15 \%$, and 12\% less than their otherrace counterparts, all other variables being constant. If the head of the household is married, there is an increase in expenditures by about $22-23 \%$ regardless of the sex of the head of the household.

Model 3 Results: Model 3 results reflect similar outcomes and differences between male and female-headed households. It is also interesting that our sample size went down to about $10 \%$ of the original sample once we included these the entertainment and apparel expenditure variables due to missing information within these categories in the dataset. Curiously enough, the impacts of variables such as education, race/ethnicity, and marriage show drastic differences once the entertainment and apparel expenditures were added as independent variables to Model 2. The direct impact of educational level of head of household decreased by about $3 \%$ in both male and femaleheaded households. The expenditures for white, black, and Hispanic male-headed households decreased significantly and sizably as did the expenditures for white, black, and Hispanic femaleheaded households as compared to their otherrace counterparts.

The coefficients of the marriage variable also declined sizably and significantly in both male and female-headed household models. Since the entertainment and apparel expenditure variables are also in the log form, their coefficients reflect the elasticity of total expenditures with respect to these. A $1 \%$ increase in entertainment expenditures results in a $0.07 \%$ increase in total expenditures for male-headed households and $0.08 \%$ increase in total expenditures for female-headed households. A $1 \%$ increase in apparel expenditures results in a $0.09 \%$ increase in total expenditures 
for male-headed and $0.14 \%$ increase in total expenditures of female-headed households. Thus, there are some significant interactions going on between the entertainment and apparel expenditures and the other independent variables in this model.

Table 3. OLS Regression Results: Model 1 (base), Model 2 (log-lin), Model 3 (expanded log-lin)

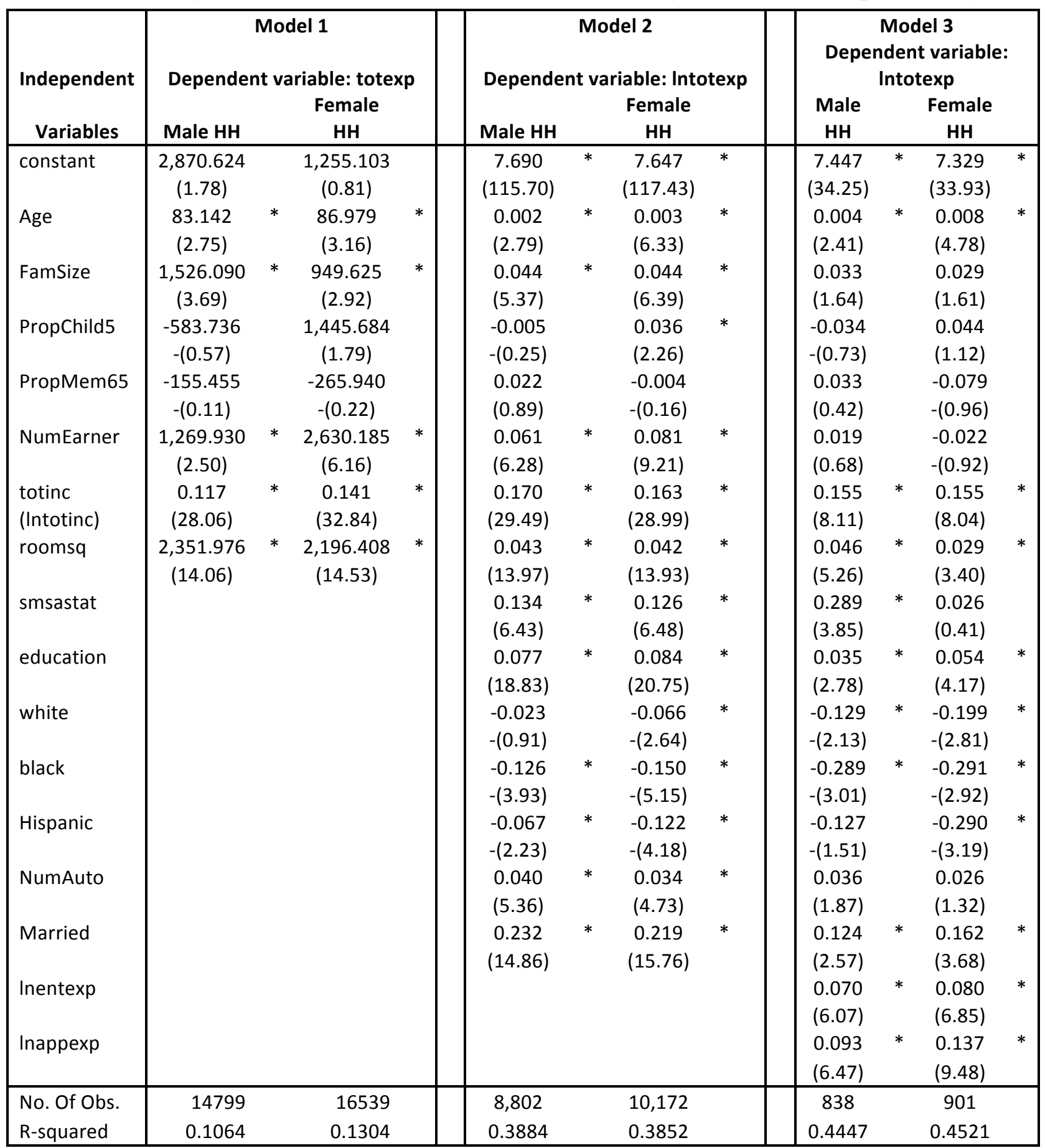

$* *$ t-stats are in parentheses; Asterix indicates that the coefficients are significant at $95 \%$.

Source: Consumer Expenditure Surveys 2016-2017 (BLS, 2018)

Table 4 shows the results from Models 4 and 5, which consider the entertainment and apparel expenditures respectively as the dependent variables. These are also log-lin models and should be interpreted with care. Before we discuss the results of the models by head-of-household, let us quickly look at the general results for all households in terms of expenditures on entertainment and apparel (Model 4 and Model 5 "All"). In the case of entertainment expenditures, there are only 2,217 households in the sample and there are 10,727 households in the apparel expenditures model. 
The $\mathrm{R}^{2}$ values for each indicate that only about $12 \%$ of the variation in entertainment expenditures can be explained using Model 4 , whereas $23 \%$ of the variations in apparel expenditures can be explained using Model 5. The variable sex refers to the sex of the head of the household and we see that male-headed households have higher entertainment expenditures than female-headed households, while female-headed households have higher apparel expenditures than male-headed households. This confirms what we had initially seen in Table 2 . A $1 \%$ increase in total income results in a $0.107 \%$ increase in entertainment expenditures and a $0.038 \%$ increase in apparel expenditures.

Living in an MSA reduces entertainment expenditures by $34 \%$, which is a very surprising result because it contradicts the general belief that living in MSAs would result in easier access, and therefore higher spending on entertainment. On the other hand, living outside MSAs could result in having to travel, and therefore spending higher amounts on entertainment than those that live within MSAs. Families with a white head-of-household spend 35\% more than the non-white head-of household families on entertainment. An equivalent impact is not seen in black or Hispanic headed households. A higher number of cars reduces the entertainment expenditures at $8 \%$ per additional automobile. Moreover, as total expenditures increase by $1 \%$, the entertainment expenditure increases by $0.69 \%$. If we compare these to the apparel expenditures, we find that households with a black head of household spend about $15 \%$ more on apparel than others and households with Hispanic head of household spend about $19.7 \%$ more on apparel than others. While the marriage variable does not impact entertainment expenditures, it does have a negative impact of about 5.7\% on apparel expenditures. An increase of $1 \%$ in total expenditures results in an increase of $0.778 \%$ on apparel purchases.

Results of Models 4a and 4b: Both Models 4a and $4 b$ have low $R^{2}$ values, 0.1178 and 0.1362 respectively, showing that the identified determinants are not explaining too much of the variation in entertainment expenditures of a household. However, there are some key differences that can be seen between the male-headed and female-headed households in terms of entertainment expenditures. As income increases by $1 \%$ in male-headed households, the entertainment expenditures increase by about $0.15 \%$, while there is no significant impact of income increase in female-headed households. Similarly, while MSA residency decreases entertainment expenditures by $42 \%$ in male-headed households, there is no impact measured in female-headed households in our sample. White male-headed households spend $44 \%$ more on entertainment expenditures as compared to other male-headed households but there is no significant impact seen in female-headed households of any race or ethnicity. While number of automobiles is not a significant determinant of entertainment expenditures in male-headed households, each additional vehicle in female-headed households reduces entertainment expenditures by $9 \%$. Male-headed households only show an impact of $0.65 \%$ increase in entertainment expenditures for every $1 \%$ increase in total expenditures, but female-headed households show a $0.72 \%$ increase.

Results of Models 5a and 5b: The results of Models $5 \mathrm{a}$ and $5 \mathrm{~b}$ that consider apparel expenditures as the dependent variable are a little more robust than Model 4 results with coefficients of determination of 0.2408 and 0.2292 , respectively for male and female-headed households. Age plays a significant role in reducing apparel expenditures for both types of households, at comparable values of $0.6 \%$ and $0.7 \%$ respectively. An increase in family size results in an $8 \%$ increase in apparel expenditures in male-headed households, but there is no significant impact on apparel expenditures in female-headed households. An increase in the number of children under 5 years of age increases apparel expenditures in female-headed households by about $15 \%$ but has no significant impact in male-headed households.

Interestingly, an increase in the number of earners in male-headed household reduces expenditures on apparel by $7 \%$ but has no impact in female-headed households. Black femaleheaded households have $16 \%$ higher and Hispanic female-headed households have $20 \%$ expenditures on apparel than other female-headed households. Another surprising result is that married male-headed households do not show any impact on apparel purchases, but married femaleheaded households spend 14\% less on apparel than their counterparts. Each additional percent of 
total expenditures results in a $0.81 \%$ increase for male-headed and $0.74 \%$ increase for femaleheaded households in apparel expenses.

Table 4. OLS Regression Results: Model 4 (Inentexp) and Model 5(Inappexp)

\begin{tabular}{|c|c|c|c|c|c|c|c|c|c|c|c|c|}
\hline \multirow{2}{*}{$\begin{array}{l}\text { Independent } \\
\text { Variables }\end{array}$} & \multicolumn{6}{|c|}{$\begin{array}{c}\text { Model } 4 \\
\text { Dependent Var: Inentexp }\end{array}$} & \multicolumn{6}{|c|}{$\begin{array}{c}\text { Model } 5 \\
\text { Dependent Var: Inappexp }\end{array}$} \\
\hline & All & & $\begin{array}{c}\text { Male } \\
\text { HH (4a) }\end{array}$ & & $\begin{array}{l}\text { Female } \\
\mathrm{HH}(4 \mathrm{~b})\end{array}$ & & All & & $\begin{array}{c}\text { Male HH } \\
\text { (5a) }\end{array}$ & & $\begin{array}{l}\text { Female } \\
\mathrm{HH}(5 \mathrm{~b})\end{array}$ & \\
\hline constant & $\begin{array}{l}-2.450 \\
-(4.26)\end{array}$ & $*$ & $\begin{array}{l}-2.167 \\
-(2.59)\end{array}$ & $*$ & $\begin{array}{l}-2.521 \\
-(3.16)\end{array}$ & $*$ & $\begin{array}{l}-4.008 \\
-(20.53)\end{array}$ & $*$ & $\begin{array}{l}-4.350 \\
-(14.77)\end{array}$ & $*$ & $\begin{array}{c}-3.794 \\
-(14.56)\end{array}$ & $*$ \\
\hline Sex & $\begin{array}{l}0.141 \\
(2.29)\end{array}$ & $*$ & & & & & $\begin{array}{l}-0.116 \\
-(5.10)\end{array}$ & $*$ & & & & \\
\hline Age & $\begin{array}{c}0.000 \\
-(0.15)\end{array}$ & & $\begin{array}{l}-0.002 \\
-(0.50)\end{array}$ & & $\begin{array}{l}0.003 \\
(0.73)\end{array}$ & & $\begin{array}{l}-0.006 \\
-(6.01)\end{array}$ & $*$ & $\begin{array}{l}-0.007 \\
-(4.76)\end{array}$ & $*$ & $\begin{array}{l}-0.006 \\
-(4.61)\end{array}$ & $*$ \\
\hline FamSize & $\begin{array}{l}-0.055 \\
-(1.55)\end{array}$ & & $\begin{array}{l}-0.063 \\
-(1.14)\end{array}$ & & $\begin{array}{l}-0.037 \\
-(0.79)\end{array}$ & & $\begin{array}{l}0.041 \\
(3.10)\end{array}$ & $*$ & $\begin{array}{l}0.080 \\
(3.66)\end{array}$ & $*$ & $\begin{array}{l}0.018 \\
(1.04)\end{array}$ & \\
\hline PropChild5 & $\begin{array}{l}-0.123 \\
-(1.58)\end{array}$ & & $\begin{array}{l}-0.147 \\
-(1.16)\end{array}$ & & $\begin{array}{l}-0.084 \\
-(0.84)\end{array}$ & & $\begin{array}{l}0.129 \\
(4.26)\end{array}$ & $*$ & $\begin{array}{l}0.070 \\
(1.43)\end{array}$ & & $\begin{array}{l}0.152 \\
(3.88)\end{array}$ & $*$ \\
\hline PropMem65 & $\begin{array}{l}-0.204 \\
-(1.46)\end{array}$ & & $\begin{array}{l}-0.205 \\
-(1.04)\end{array}$ & & $\begin{array}{l}-0.214 \\
-(1.07)\end{array}$ & & $\begin{array}{l}-0.100 \\
-(2.13)\end{array}$ & $*$ & $\begin{array}{l}-0.124 \\
-(1.77)\end{array}$ & & $\begin{array}{l}-0.065 \\
-(1.03)\end{array}$ & \\
\hline NumEarner & $\begin{array}{l}0.021 \\
(0.46)\end{array}$ & & $\begin{array}{l}-0.027 \\
-(0.38)\end{array}$ & & $\begin{array}{l}0.058 \\
(0.93)\end{array}$ & & $\begin{array}{l}-0.042 \\
-(2.47)\end{array}$ & $*$ & $\begin{array}{l}-0.077 \\
-(2.92)\end{array}$ & $*$ & $\begin{array}{l}-0.020 \\
-(0.90)\end{array}$ & \\
\hline Intotinc & $\begin{array}{l}0.107 \\
(3.01)\end{array}$ & $*$ & $\begin{array}{l}0.156 \\
(3.06)\end{array}$ & $*$ & $\begin{array}{l}0.053 \\
(1.07)\end{array}$ & & $\begin{array}{l}0.038 \\
(3.27)\end{array}$ & $*$ & $\begin{array}{l}0.032 \\
(1.87)\end{array}$ & & $\begin{array}{l}0.044 \\
(2.81)\end{array}$ & $*$ \\
\hline roomsq & $\begin{array}{l}0.017 \\
(1.07)\end{array}$ & & $\begin{array}{l}0.024 \\
(1.04)\end{array}$ & & $\begin{array}{l}0.008 \\
(0.35)\end{array}$ & & $\begin{array}{l}0.000 \\
(0.08)\end{array}$ & & $\begin{array}{l}-0.013 \\
-(1.69)\end{array}$ & & $\begin{array}{l}0.015 \\
(1.91)\end{array}$ & \\
\hline smsastat & $\begin{array}{l}-0.342 \\
-(3.09)\end{array}$ & * & $\begin{array}{l}-0.421 \\
-(2.47)\end{array}$ & $*$ & $\begin{array}{l}-0.240 \\
-(1.63)\end{array}$ & & $\begin{array}{l}0.044 \\
(1.04)\end{array}$ & & $\begin{array}{l}0.040 \\
(0.60)\end{array}$ & & $\begin{array}{l}0.040 \\
(0.75)\end{array}$ & \\
\hline education & $\begin{array}{l}-0.030 \\
-(1.36)\end{array}$ & & $\begin{array}{l}-0.037 \\
-(1.15)\end{array}$ & & $\begin{array}{l}-0.021 \\
-(0.65)\end{array}$ & & $\begin{array}{l}0.000 \\
(0.04)\end{array}$ & & $\begin{array}{l}-0.013 \\
-(1.15)\end{array}$ & & $\begin{array}{l}0.009 \\
(0.80)\end{array}$ & \\
\hline white & $\begin{array}{l}0.350 \\
(2.93)\end{array}$ & $*$ & $\begin{array}{l}0.440 \\
(2.74)\end{array}$ & $*$ & $\begin{array}{l}0.163 \\
(0.90)\end{array}$ & & $\begin{array}{l}0.042 \\
(0.94)\end{array}$ & & $\begin{array}{l}0.031 \\
(0.48)\end{array}$ & & $\begin{array}{l}0.051 \\
(0.84)\end{array}$ & \\
\hline black & $\begin{array}{l}0.265 \\
(1.50)\end{array}$ & & $\begin{array}{l}0.230 \\
(0.92)\end{array}$ & & $\begin{array}{l}0.205 \\
(0.81)\end{array}$ & & $\begin{array}{l}0.154 \\
(2.87)\end{array}$ & $*$ & $\begin{array}{l}0.142 \\
(1.73)\end{array}$ & & $\begin{array}{l}0.163 \\
(2.28)\end{array}$ & $*$ \\
\hline Hispanic & $\begin{array}{l}0.281 \\
(1.80)\end{array}$ & & $\begin{array}{l}0.290 \\
(1.32)\end{array}$ & & $\begin{array}{l}0.151 \\
(0.67)\end{array}$ & & $\begin{array}{l}0.197 \\
(3.75)\end{array}$ & $*$ & $\begin{array}{l}0.189 \\
(2.42)\end{array}$ & $*$ & $\begin{array}{l}0.202 \\
(2.85)\end{array}$ & * \\
\hline NumAuto & $\begin{array}{l}-0.080 \\
-(2.45)\end{array}$ & $*$ & $\begin{array}{l}-0.071 \\
-(1.41)\end{array}$ & & $\begin{array}{l}-0.094 \\
-(2.16)\end{array}$ & $*$ & $\begin{array}{l}-0.025 \\
-(1.80)\end{array}$ & & $\begin{array}{l}-0.022 \\
-(1.07)\end{array}$ & & $\begin{array}{l}-0.027 \\
-(1.44)\end{array}$ & \\
\hline Married & $\begin{array}{l}-0.072 \\
-(0.88)\end{array}$ & & $\begin{array}{l}-0.205 \\
-(1.67)\end{array}$ & & $\begin{array}{l}0.084 \\
(0.75)\end{array}$ & & $\begin{array}{l}-0.057 \\
-(2.04)\end{array}$ & $*$ & $\begin{array}{l}0.053 \\
(1.21)\end{array}$ & & $\begin{array}{l}-0.143 \\
-(3.93)\end{array}$ & * \\
\hline Intotexp & $\begin{array}{c}0.690 \\
(12.52) \\
\end{array}$ & $*$ & $\begin{array}{l}0.650 \\
(8.04) \\
\end{array}$ & $*$ & $\begin{array}{l}0.723 \\
(9.46) \\
\end{array}$ & $*$ & $\begin{array}{c}0.778 \\
(39.60) \\
\end{array}$ & $*$ & $\begin{array}{c}0.816 \\
(27.23) \\
\end{array}$ & $*$ & $\begin{array}{c}0.748 \\
(28.76) \\
\end{array}$ & $*$ \\
\hline No. of Obs. & 2,217 & & 1,099 & & 1,118 & & 10,727 & & 4,882 & & 5,845 & \\
\hline R-squared & 0.1241 & & 0.1178 & & 0.1362 & & 0.2324 & & 0.2408 & & 0.2292 & \\
\hline
\end{tabular}

$* * \mathrm{t}$-stats are in parentheses, Asterix indicates that the coefficients are significant at $95 \%$

Source: Consumer Expenditure Surveys 2016-2017 (BLS 2018)

\section{Conclusions}

Our findings from all the Models indicate that male and female-headed households behave very differently in terms of their expenditure profiles. Factors such as age of head of household, education, total income, family size, number of earners in the family, number of children below age five, residing in MSA, number of cars, race, ethnicity, and marital status all contribute to determining household expenditures. The models presented in this paper able to explain about $38 \%$ of variation in household expenditures based on these characteristics and therefore offer an insight into how male and female 
households can be targeted differently by producers and suppliers who are attempting to increase their marketing effectiveness.

Expenditures on entertainment are higher in male-headed households that are also likely to have higher incomes than female-headed households. Moreover, white male-headed household have much higher entertainment expenditures than other male-headed households. On the other hand, expenditures on apparel are higher in female-headed households, with black and Hispanic female-headed households showing a higher propensity to consume apparel as compared to other female-headed households. A marginally sexist observation is also that households with married women as the head of the household are likely to spend about $14 \%$ less on apparel than their counterparts. This paper is not in any way a complete picture of what determines expenditures on apparel or entertainment for a family in the United States. There are too many preferences, choices, and other tangible or non-tangible determinants that still need to be identified and studied in a meaningful manner. However, this paper is the first step in beginning to identify the determinants of specific types of expenditures that occur within all households.

\section{References}

Bahety, P. 2016. "How Third Party Online Reviews Influence Automobile Sales.” ProQuest Dissertations Publishing.

Bahng, Y., \& Kincade, D. 2013. "College students' apparel shopping orientation and brand/product preferences." Journal of Fashion Marketing and Management 17(3): 367-384.

Balter, D., \& Butman, J. 2005. Deep Inside the Hive: More Reports From the Bzzagents. Grapevine: The New Art of Word of Mouth Marketing. London, England: Penguin Books Ltd.

BLS 2018. Bureau of Labor Statistics, U.S. Department of Labor. Retrieved September 9, 2018, from Consumer Expenditure Survey (CE): https://www.bls.gov/data/.

Charron-Chenier, R., \& Mueller, C. 2018. Racial Disparities in Medical Spending: Healthcare Expenditures for Black and White Households (2013-2015). Race and Social Problems 10(1), 10(2); 113-133. Doi:10.1007/s12552018-9226-4.

Fadiga, M., Misra, S., \& Ramirez, O. 2005. "US consumer purchasing decisions and demand for apparel." Journal of Fashion Marketing and Management 9(4): 367-379.

Fagerstrom, A., Ghinea, G., \& Sydnes, L. 2015. "How Does Probability Impact Consumers' Choice? The Case of Online Reviews." Managerial and Decision Economics 37(4-5). Doi:https://doi.org/10.1002/mde.2720.

Fatima, A., \& Ahmad, Z. 2013. Estimation of Household Expenditures on the Basis of Household Characteristics by Gender. The Pakistan Journal of Social Issues 4: 1-15.

Guzman, J., Morrison, A., \& Sjoblom, M. 2008. "The Impact of Remittances and Gender on Household Expenditure Patterns: Evidence from Ghana." In The International Migration of Women (pp. 125-152). Basingstoke, Hampshire: Palgrave-Macmillan.

Harris, J. M., \& Shiptsova, R. 2007. "Consumer Demand for Convenience Foods: Demographics and Expenditures." Journal of Food Distribution Research 38(3): 22-36.

Hu, N., Liu, L., \& Zhang, J. J. 2008. "Do Online Reviews Affect Product Sales? The Role of Reviewer: Characteristics and Temporal Effects." Information Technology and Management 9(3): 201-214.

Kalwij, A., \& Salverda, W. 2007. "The Effects of Changes in Household Demographics and Employment on Consumer Demand Patterns." Applied Economics 39(11): 1447-1460.

Keller, E. B., \& Fay, B. 2012. The Face-to-FaceBook: Why Real Relationships Rule in a Digital Marketplace. New York: Free Press.

Sawtelle, B. 1993. "Income Elasticities of Household Expenditures - a US Cross-Section Perspective." Applied Economics 25(5): 635 .

Scheerder, J., Vos, S., \& Taks, M. 2011. "Expenditures on Sport Apparel.” Creating Consumer Profiles through Interval Regression Modelling.

Shih, C. C. 2010. The Facebook Era: Tapping Online Social Networks to Market, Sell, and Innovate. Upper Saddle River, N.J.: Prentice Hall.

Tang, W., Aggarwal, A., Liu, Z., Acheson, M., Rehm, C., Moudon, A., \& Drewnowski, A. 2016. "Validating Selfreported Food Expenditures Against Foodstore and Eating-out Receipts." European Journal of Clinical Nutrition 70(3): 352-357.

Wright, T. 2015. Fizz: Harness the Power of Word-Of-Mouth Marketing to Drive Brand Growth. New York: McGrawHill Education.

Yousaf, U., Altaf, M., Sarwar, N., \& Shah, S. 2012. "Hesitancy Towards Online Shopping: A Study of Pakistani Consumers." Management \& Marketing 2: 273-284.

Zhen, C., Taylor, J., Muth, M., \& Leibtag, E. 2009. "Understanding Differences in Self Reported Expenditures between Household Scanner Data and Diary Survey Data: A Comparison of Homescan and Consumer Expenditure Survey." Review of Agricultural Economics 31(3): 470-492. 